\title{
Seed-coat thickness explains contrasting germination responses to smoke and heat by Leucadendron species
}

\author{
Byron B. Lamont ${ }^{1 *}$, Pablo Gómez Barreiro ${ }^{2}$ and Rosemary J. Newton ${ }^{2}$
}

${ }^{1}$ School of Molecular and Life Sciences (Ecology Section), Curtin University, PO Box U1987, Perth, WA 6845, Australia

${ }^{2}$ Science Directorate, Royal Botanic Gardens Kew, Wakehurst Place, Ardingly, West Sussex, RH17 6TN, United Kingdom

* Corresponding author:

1 Prof Byron Lamont, School of Molecular and Life Sciences, Curtin University, Perth,

2 Australia. Email: B.Lamont@ curtin.edu.au

3

4

5

6 Running head: Fire, seed-coat thickness and germination 


\section{Highlight}

2 We show Leucadendron seeds are either plant-stored with thin, highly permeable seed-coats

3 that germinate readily; or soil-stored and the thicker their seed-coat, the lower their

4 permeability and greater their need for smoke/heat to promote germination.

\section{Abstract}

7 Fire stimulates germination of most seeds in fire-prone vegetation. Fruits of Leucadendron

8 (Proteaceae) are winged achenes or nutlets that correlate with their requirements for smoke

9 and/or heat in promoting germination. We describe five possible smoke-heat dormancyrelease/germination syndromes among plants, of which Leucadendron displays three (no response, smoke only, smoke and heat). As seed-coat thickness varies with seed-storage location (plant or soil) and morphology (winged or wingless), we tested its possible role in water uptake and germination. Species with winged seeds achieved 100\% germination in the absence of smoke/heat, seed coats were an order of magnitude thinner, and their permeability greatly exceeded that of nutlets. As seed-coat thickness increased a) imbibitional water uptake declined at a decreasing rate, and b) the response to smoke, and to a lesser extent heat, increased linearly to reach levels of germination approaching those of winged seeds. For species responsive to smoke and heat, there was no additive effect when applied together, suggesting that they may have promoted the same physiological process. By what mechanisms a) the smoke response is greater the thicker the seed coat, and b) smoke chemicals could increase water permeability to explain the non-additive effect of smoke and heat, warrant further investigation.

Keywords: heat, Leucadendron, Mediterranean-type ecosystems, seed-coat thickness, seed permeability, serotiny, smoke, soil-stored seeds

\section{Introduction}

Seeds in temperate, fire-prone ecosystems are usually stored in the soil but, in some regions, on the plant as well (Rundel et al., 2018). Three germination syndromes can be recognized in response to a summer-autumn fire event. 1: Soil-stored seeds that are impermeable to water rely on fire-heat to render them permeable before they can germinate (Tangney et al., 2020). 2: Soil-stored seeds that are permeable to water rely on smoke-associated chemicals to promote germination (Moreira et al., 2010). 3 Seeds stored on the plant (serotiny) are released from their 
35

and germinate as soon as substantial rain falls and daily temperatures drop below a threshold (Lamont et al., 2020). These three syndromes are usually considered discrete but there are increasing reports of their overlap. For example, despite insulation by their supporting structures, serotinous seeds are exposed to heat during a fire and a heat pre-treatment may sometimes promote germination (Midgley and Viviers, 1990; Hanley and Lamont, 2000). Some serotinous seeds may even respond to smoke chemicals that are released from soil particles following rain (Preston and Baldwin, 1999; Brown and Botha, 2004). Of particular interest are the (unexpected) reports of responses by species with soil-stored seeds to both smoke and heat (Kenny, 2000; Morris, 2000; Mackenzie et al., 2016). None of these studies sought to explain how these two fire-related factors could interact to break dormancy.

Newton et al. (2021) examined smoke and heat effects on the germination of 40 Leucadendron species. Fruits in this genus are single-seeded and thus can be treated as seeds; thus their pericarps are called seed coats. Untreated seeds of all but two of 31 serotinous species showed high levels of germination without any pre-treatment (mean of $96 \%$ at $20 / 10^{\circ} \mathrm{C}$ diurnal treatment in water agar, Table S1). Both serotinous species with poor control germination had nutlets rather than the winged achenes of the other serotinous species and either responded positively to aqueous smoke (L. linifolium) or germinated poorly $(<50 \%)$, irrespective of treatment (L. album). Smoke promoted germination in seven species that possessed nutlets (increasing from a mean of $24 \%$ among the controls to $92 \%$ germination when smoke-treated); of these, five were unaffected by 20 minutes of heat at $80^{\circ} \mathrm{C}$ and heat promoted germination in two. In other studies, germination of L. daphnoides and L. tinctum was quadrupled by scarification or removing the embryo from the seed (Brown and van Staden, 1973; Brown and Dix, 1985), consistent with physical barriers to germination. For the closely related Leucospermum, Brits and Manning (2019) showed that high temperatures resulted in desiccation and tearing of the endotesta that removed its impermeability to oxygen and enabled germination to occur.

Soil-stored nutlets can be expected to have thick seed coats to ensure resistance against decay agents, granivores and the digestive tract of animal dispersers (Calviño-Cancela et al., 2008; Hudaib, 2019; Dalling et al., 2020) and eventually fire heat, whereas serotinous seeds are protected and insulated by their supporting woody fruits or cones (Lamont et al., 2020). The latter can be expected to have thin seed coats since they germinate as soon as the soil is cool and moist. Thus, we wondered if seed-coat thickness might play a role in explaining the differences in germination requirements between these seed types. For example, water permeability decreases with increasing seed-coat thickness, independent of its hardness, in various legumes and grasses (Noodén et al., 1985; Frączek et al., 2005; Richard et al., 2018). 
70 Seeds that respond to fire-type heat usually have thick, dense, cutinized coats that are

71 impermeable to fluids until heat opens up the dedicated 'water gap' in the seed coat (Moreira $e t$

72 al., 2010; Gama-Arachchige et al., 2013; Burrows et al., 2018). Among other species whose

73 germination is promoted by heat (Hanley and Lamont, 2000; Kenny, 2000), no water gap is

74 evident and general tearing of seed coat tissues seems to be involved (Brits and Manning,

75 2019).

Seeds that respond to smoke are weakly to moderately permeable (Moreira et al., 2010).

This indicates a compromise in seed-coat thickness between protecting the embryo from

deleterious agents in its environment and allowing smoke chemicals to reach the embryo. Thus, seed-coat thickness might provide a clue as to whether, and what sort of, a fire-related property is required to overcome embryo dormancy in Leucadendron. If the seed coat is thin, consistent with lack of soil storage and readiness to germinate as soon as dispersed, then the seeds will be highly permeable and there should be no fire response; if the coat is sufficiently thick to render it tardily permeable then the seeds will respond to heat; if the coat is moderately permeable then it will allow smoke chemicals to enter the seed and act catalytically (Flematti et al., 2004; Lamont et al., 2019) or increase its water permeability (Ghebrehiwot et al., 2008; Jain et al., 2008).

1. The need for smoke and/or heat to promote germination of Leucadendron species is a function of seed-coat thickness;

2. Imbibitional water uptake is a negative function of seed-coat thickness and is inversely correlated with the promotory effect of smoke and/or heat on germination;

3. Serotinous seeds in winged fruits germinate readily in the absence if fire-related properties will have thin seed coats that are highly permeable to water, whereas nutlets that require smoke and/or heat to stimulate germination have relatively thick seed coats that are only weakly permeable.

\section{Materials and methods}

98 The 40 species of Leucadendron examined are given in Table 1. The experimental design, 99 involving controls, smoke, heat and (smoke + heat) pre-treatments, is described in Newton et

100 al. (2021). L. tinctum showed low germination levels under all treatments and was not included

101 in the analyses (but is considered in the Discussion). Five representative intact seeds were

102 selected from the collections used for the germination experiments. Pericarps were bisected

103 manually with a microtome blade. They were then positioned with the cut surface held 104 horizontally under a Stemi dissecting stereoscope, model SV11, with a camera (AxioCam, Carl 
105 Zeiss, UK) attachment. Distance between outer and inner surfaces of the pericarp were

106 measured in mm to 4 decimal places (AxioVision 4.8.1, Carl Zeiss). To examine the extent to

107 which water permeability was a function of seed-coat thickness, 13 species were chosen to

108 cover the three seed types and the full range of seed-coat thicknesses. Ten representative seeds

109 per species were selected and their air-dry weights taken. Seeds were individually immersed in

110 distilled water using a compartmentalized Petri dish, patted dry and weighed to $0.1 \mathrm{mg}$ with a

111 microbalance (UMT2, Mettler, Toledo) at 1, 3, 7, 24, 48 and 72-hour intervals, returning the

112 seeds to the Petri dishes each time. Water content, expressed as a percentage, was determined

113 as (wet weight minus dry weight)/dry weight and only the final result is reported here as only

114 then had imbibition stabilized.

115 The statistical methods and allocation to smoke and/or heat responsiveness followed

116 Newton et al. (2021). Germination data for the controls and treatment giving the highest mean

117 result were extracted from Table S5 of Newton et al. (2021) and plotted against the seed-coat

118 thicknesses obtained here. An increase in germination of $10 \%$ was selected as the minimum

119 effect size of biological interest, with at least $95 \%$ confidence to separate non-trivial from

120 trivial effects. Results with insufficient evidence to distinguish trivial from non-trivial effects

121 were classified as 'uncertain' (Newton et al., 2021). The difference between germination levels

122 of the controls and the three fire-related pre-treatments, and \% water absorbed after $72 \mathrm{~h}$, were

123 plotted against mean seed-coat thicknesses. The lines with highest coefficients of determination

$124\left(R^{2}\right)$ among four curvilinear options [R (https://www.stats.bris.ac.uk/R) or Microsoft@ Word

125 for Mac 2011] were fitted to the data. Germination and seed-coat thickness data for species

126 with winged, and non-winged plant or soil-stored seeds, or that did or not respond to fire-type

127 properties were also grouped and compared by conventional ANOVA/Tukey's statistics

128 (http://vassarstats.net, R. Lowry@).

\section{$130 \quad$ Results}

131 Thirteen species, all plant-stored with winged seeds and seed-coat thickness of $45 \pm 19 \mu \mathrm{m}$

132 (mean $\pm \mathrm{SD}$ ), germinated at $\sim 100 \%$ among the controls. For the remaining 26 species (omitting

133 L. tinctum), data for the controls fitted the linear equation: $\mathrm{Y}=-0.13 \mathrm{X}+91.01$ where $\mathrm{Y}=\%$

134 germination and $\mathrm{X}=$ seed-coat thickness in $\mu \mathrm{m}(R=0.543, P=0.0041)$. Thus, estimated $\mathrm{Y}=$

$13590.4 \%$ when $\mathrm{X}=50 \mu \mathrm{m}$, and $\mathrm{Y}=13.0 \%$ when $\mathrm{X}=600 \mu \mathrm{m}$ (the limit of seed-coat thicknesses

136 recorded here). For the treatment yielding greatest response to smoke and/or heat, $\mathrm{Y}=95.8 \%$

$137(R=0.123, P=0.5541)$, independent of seed-coat thickness, i.e., the treatment brought mean

138 germination almost to the level of the 13 species not requiring any treatment to yield $100 \%$

139 germination. 
Overall, the difference between germination levels of the controls and those treated with heat $(\Delta \%)$ increased slightly with increase in seed-coat thickness, with zero difference at $23 \mu \mathrm{m}$ and $10.7 \%$ at $600 \mu \mathrm{m}$ (Fig. 1a). Addition of smoke increased the mean difference to $35.5 \%$ at

$143600 \mu \mathrm{m}$ (Fig. 1b). Addition of smoke plus heat gave no further increase with a mean difference of $36.5 \%$ at $600 \mu \mathrm{m}$ (Fig. 1c).

The 13 species selected for study of imbibition showed similar trends to the total species in the study: these best obeyed a negative logarithmic function, with the controls ranging from $\sim 100 \%$ germination at $\sim 25 \mu \mathrm{m}$ to $\sim 10 \%$ at $\sim 600 \mu \mathrm{m}$. As an index of

148 permeability, seed water content after soaking for $72 \mathrm{~h}$ best declined in a power-function 149 manner with increasing seed-coat thickness (Fig. 2). Estimated mean water content fell from $150 \sim 60 \%$ at $\sim 25 \mu \mathrm{m}$ seed-coat thickness to $\sim 42 \%$ at $140 \mu \mathrm{m}$ (the range of thickness values for winged achenes), and $\sim 50 \%$ at $\sim 50 \mu \mathrm{m}$ to $\sim 30 \%$ at $600 \mu \mathrm{m}$ (the range for nutlets).

Placing the data into the three location-morphology categories summarizes the previous results (Fig. 3). Germination responses to smoke (and heat) increased from winged to nonwinged plant-stored seeds to soil-stored seeds. However, seed-coat thicknesses of the nutlets, whether plant- or soil-stored, were on average about six times thicker than the winged achenes (Fig. 3B). The only plant-stored seeds not to require a fire-related property for high germination levels were winged (74\%); the only plant-stored seeds benefitting from smoke and/or heat were nutlets $(10 \%)$ and their seed coats were $>7$ times thicker on average, although with a large error term (Fig. 3C). All but 12\% (one species uncertain) of the soil-stored nutlets responded to fire-related properties, particularly smoke.

\section{Discussion}

163 Among fire-prone seed plants generally, five fire-response dormancy-release/germination syndromes can be recognized (Table 3). Leucadendron has representatives in three of them: syndrome 1 with almost all species having plant-stored, winged, single-seeded fruits lacking any need for a fire property to stimulate germination, and these possessed thin seed coats; syndrome 2 with plant/soil-stored, nutlet-bearing species responding to smoke but not heat,

168 with relatively thick seed coats; and syndrome 4 with a few soil-stored nutlet-bearing species

169 responding non-additively to both smoke and heat, also with relatively thick seed coats.

170 Overall, the thicker the seed coat, a) the lower the level of germination in the absence of fire171 related properties, and b) the greater the germination response to fire-related properties, such 172 that the difference between the controls and fire-treated seeds increased linearly with increase 173 in seed-coat thickness (Results, Fig. 1). Smoke was far more effective at increasing germination 174 levels among the species with thicker seed coats, such that the co-presence of heat made a 
175 negligible difference to the outcomes (Fig. 1b,c). Even so, fire-type heat $\left(80^{\circ} \mathrm{C}\right.$ for $\left.20 \mathrm{~min}\right)$

176 alone increased the germination response to a minor extent (Fig. 1a).

177 Thus, seed-coat thickness is a reasonable predictor of the extent to which fire-related

178 properties, especially smoke, will bring germination levels up to those of species that do not

179 require heat or smoke $(\sim 100 \%)$. Water permeability is an inverse function of seed-coat

180 thickness (as also shown by Noodén et al., 1985; Frączek et al., 2005), with winged achenes

181 (seed-coat thickness 25-140 $\mu \mathrm{m}$ ) much more permeable than nutlets $(150-600 \mu \mathrm{m})$, such that

182 seed permeability declined in a power-function manner (best-fit curve). Since the amount of

183 smoke chemicals absorbed is a function of water uptake (Baxter et al., 1994), and thicker seed

184 coats are less permeable (shown here), it raises the possibility that (at least some of) these

185 promotive chemicals serve to increase permeability to water and/or oxygen (Brown and van

186 Staden, 1973; Ghebrehiwot et al., 2008; Jain et al., 2008; Brits and Manning, 2019).

187 Of the ten species with biologically significant smoke responses, two (L. elimense, $L$.

188 thymifolium) responded significantly to both smoke and heat. Heat and smoke can be

189 distributed patchily during a fire (Auld and Bradstock, 1996) and the ability to respond to more

190 than one germination property has been suggested to maximise the capability of seeds to sense

191 the passage of a fire (Kenny, 2000; Morris, 2000). Once heated, the hard seeds of many

192 legumes become permeable (Burrows et al., 2018) and will now germinate as soon as the soil is

193 moist and cool, so that smoke sensitivity would be redundant. Smoke-sensitive seeds are stored

194 in a permeable state that allows smoke chemicals after fire to enter them, so that now heat-

195 sensitivity is redundant. However, it is possible for smoke chemicals to drift into unburnt or

196 scorched patches through diffusion and leaching (Ghebrehiwot et al., 2013), where the seeds

197 are unlikely to have received a heat treatment. However, patches already occupied by plants are

198 unlikely to lead to recruitment because they are outcompeted by the plants already present

199 (Lamont et al., 2019). Thus, a dual response is most likely to be adaptive when a) seeds are in

200 patches that will receive both heat and smoke, and b) the response is additive, especially if it is

201 synergistic (syndrome 5A/B in Table 2).

202 In a worldwide survey of 589 species subjected experimentally to both heat and smoke,

$20314.5 \%$ responded positively to both heat and smoke (BBL, unpublished) so that this

204 phenomenon is not common but it is also not rare. In some cases, hard seeds become smoke-

205 sensitive after they are heated and there is an additive or synergistic effect (Zirondi et al., 2019;

206 syndrome 5A/B). The logical interpretation is that these environmental properties affect

207 different processes that are well-known: heat renders the seeds permeable and smoke chemicals

208 have a catalytic effect on the seed's physiology. However, for Leucadendron, the two heat-

209 responsive species were not impermeable to water, and their seed-coat thickness and 
210 permeability were not greater than some other smoke-responsive-only species (Fig. 2). Further,

211 germination was no greater than with smoke plus heat than with smoke alone. But germination

212 was greater than with heat alone that in turn was greater than for the controls.

213 These responses imply that smoke and heat may affect the same process (syndrome 4).

214 Since heat probably increases permeability (no other function for a fire-type heat pulse on

215 dormant seeds is known), and the thicker the seed coat the proportionately greater the smoke

216 response, it seems in this case that heat supplements the permeability-enhancing role of smoke

217 chemicals (Jain et al., 2008; Ghebrehiwot et al., 2008). Although difficult to envisage a

218 relevant scenario, it appears that a non-additive response to smoke and heat is only likely to be

219 adaptive when seeds receive fire-type heat in the absence of smoke. The improbability of such

220 a situation might explain why this dual response is not better represented among fire-prone

221 floras. This topic clearly needs further investigation, especially the relative role of heat and

222 smoke in raising the permeability of non-hard seeds.

223 Our results also raise the interesting issue of L. tinctum that has $>50 \%$ greater seed-coat

224 thickness than the next thickest but germinated poorly despite high viability and did not

225 respond to any treatment. In another study with this species, germination was raised from $12 \%$

226 to $45 \%$ with smoke and to $70 \%$ with smoke plus scarification (Brown and Botha, 2004),

227 equivalent to syndrome 5 (Table 2). Brown and Dix (1985) showed that the seed coat was

228 essentially a mechanical barrier to breaking dormancy by increasing germination from $20 \%$ to

$22980 \%$ after scarifying the seeds then covering them in lanolin. If our batch had exceptionally

230 thick seed coats they could act like conventional 'hard' seeds and only respond to heat. It is

231 possible then that our heat treatment $\left(80^{\circ} \mathrm{C}\right.$ for $\left.20 \mathrm{~min}\right)$ was not 'severe' enough to scarify most

232 seeds in this species, although the complete lack of a smoke response is not easily explained.

233 That it is not just an issue of winged achenes versus nutlets is demonstrated when the

234 eight species with plant-stored nutlets are considered. These are as thick as the soil-stored

235 nutlets on average but their response to smoke is much less (Fig. 3A, B). Two were as thin as

236 the winged seeds (controls $99 \%$ germination) and six were on average $50 \mu \mathrm{m}$ thicker than the

237 mean of the soil-stored nutlets (controls 61\% germination). The three plant-stored species

238 showing a biologically significant response to smoke had seed coats five times thicker than the

239 plant-stored species that did not benefit from smoke (Fig. 3C). So, the key to their germination

240 requirements is seed-coat thickness rather than storage location or morphology. Thus, some

241 plant-stored nutlets may be just as permeable as the winged achenes as they have similar seed-

242 coat thicknesses (Fig. 2). This may have functional significance - the confines of the cone are

243 much less hazardous for survival than in the soil, and germination can proceed readily

244 following postfire release as with the winged seeds. However, the six species with thick-walled, 
245 plant-stored nutlets increase their options to remain soil-stored if they arrive in a microsite

246 conducive to germination (Lamont et al. 2021) or, if unsuitable, to remain dormant until the

247 fire.

Thick, weakly permeable seed coats serve to increase longevity and heat tolerance in the soil but then the seed must rely on a special fire-related property, smoke, as distinct from just cool wet winters, to signal (and respond to) the onset of ideal recruitment conditions. Thus, this genus possesses ideal taxa to pursue the mechanisms by which stimulatory smoke chemicals serve to break dormancy, as closely related species that do not require smoke also exist. This includes the possibility of serving to improve permeability (Ghebrehiwot et al., 2008; Jain et $a l ., 2008)$ that needs further investigation. The role of fire-type heat is usually considered to be breaking the impermeability of hard seeds. Yet here we have instances of seeds with moderate permeability that can also benefit from heat that suggests it may also serve to further increase the permeability of seeds that are already (weakly) permeable. Evidence available so far indicates that this dual response to heat and smoke may exist among many hundreds of fireprone species. This genus is ideal for pursuing the mechanisms by which seeds may respond to both smoke and heat and their functional significance.

261

\section{Acknowledgements}

263 We thank a colleague who reviewed a draft of Newton et al. (2021) for suggesting the possible

264 significance of seed-coat thickness in explaining our initial results, Berin Mackenzie for

265 introducing the concept of biological significance to this work on which this follow-up research

266 was based, and Richard Cowling and Tianhua He for early support.

\section{Author contributions}

269 BBL and RJN conceived the project and designed the experiments; PGB performed all

270 experiments and tests; BBL and PGB analysed the data; BBL and RJN wrote the draft

271 manuscript; PGB contributed to drafts and all gave final approval for publication.

\section{Conflicts of interest}

274 None.

\section{Funding}

277 This work was originally supported by the Australian Research Council (projects

278 DP120013389, DP130103029) and the Bentham-Moxon Trust, Royal Botanic Gardens, Kew, 279 receives grant-in-aid from Defra, UK. 


\section{Data availability}

Data used for this analysis are given in Table 1 here and Table S5 of Newton et al. (2021).

\section{References}

Auld TD, Bradstock RA. 1996. Soil temperatures after the passage of a fire: do they influence the germination of buried seeds? Australian Journal of Ecology 21, 106-109.

Baxter BJM, van Staden J, Granger JE, Brown NAC. 1994. Plant-derived smoke and smoke extracts stimulate seed germination of the fire-climax grass Themeda triandra. Environmental and Experimental Botany 34, 217-223.

Brits GJ, Manning JC. 2019. Seed structure and physiology in relation to recruitment ecology in Leucospermum (Proteaceae) in fynbos. Australian Journal of Botany 67, 290-308.

Brown NAC, Botha PA. 2004. Smoke seed germination studies and a guide to seed propagation of plants from the major families of the Cape Floristic Region, South Africa. South African Journal of Botany 70, 559-581.

Brown NAC, Dix L. 1985. Germination of the fruits of Leucadendron tinctum. South African Journal of Botany 51, 448-452.

Brown NAC, van Staden J. 1973. The effect of scarification, leaching, light, stratification, oxygen and applied hormones on germination of Protea compacta R.Br. and Leucadendron daphnoides Meisn. Journal of South African Botany 39, 185-195.

Burrows GE, Alden R, Robinson WA. 2018. The lens in focus - lens structure in seeds of 51 Australian Acacia species and its implications for imbibition and germination. Australian Journal of Botany 66, 398-413.

Calviño-Cancela M, He T, Lamont BB. 2008. Distribution of myrmecochorus species over the landscape and their potential long-distance dispersal by emus and kangaroos. Diversity and Distributions 14, 11-17.

Dalling JW, Davis AS, Arnold E, Sarmiento C, Zalamea P. 2020. Extending plant defence theory to seeds. Annual Review of Ecology, Evolution and Systematics 51, 123-41.

Flematti GR, Ghisalberti EL, Dixon KW, Trengove RD. 2004. A compound from smoke that promotes seed germination. Science 305, 977-977.

Frączek J, Hebda T, Ślipek Z, Kuraska S. 2005. Effect of seed-coat thickness on seed hardness. Canadian Biosystems Engineering 47, 4.1-4.5.

Gama-Arachchige NS, Baskin JM, Geneve RL, Baskin CC. 2013. Identification and 
characterization of ten new water gaps in seeds and fruits with physical dormancy and classification of water-gap complexes. Annals of Botany 112, 69-84.

Ghebrehiwot HM, Kulkarni MG, Kirkman KP, van Staden J. 2008. Smoke $\square$ water and a smoke $\square$ isolated butenolide improve germination and seedling vigour of Eragrostis tef (Zucc.) Trotter under high temperature and low osmotic potential. Journal of Agronomy and Crop Science 194, 270-277.

Ghebrehiwot HM, Kulkarni MG, Szalai G, Soós V, Balázs E, van Staden J. 2013.

Karrikinolide residues in grassland soils following fire: Implications on germination activity. South African Journal of Botany 88, 419-424.

Hanley ME, Lamont BB. 2000. Heat pre-treatment and the germination of soil- and canopystored seeds of Western Australian species. Acta Oecologia 21, 315-321.

Hudaib T. 2019. The role of seed-coat thickness in resistance/susceptibility of legumes to cowpea beetle (Callosobruchus maculatus) infestation. European Journal of Biomedical and Pharmaceutical Sciences 6, 33-35.

Jain NG, Ascough D, van Staden J. 2008. A smoke-derived butenolide alleviates $\mathrm{HgCI}_{2}$ and $\mathrm{ZnCI}_{2}$ inhibition of water uptake during germination and subsequent growth of tomatopossible involvement of aquaporins. Journal of Plant Physiology 165, 1422-1427.

Kenny BJ. 2000. Influence of multiple fire-related cues on three Sydney Grevillea (Proteaceae) species. Austral Ecology 25, 664-669.

Lamont BB, He T, Yan Z. 2019. Evolutionary history of fire-stimulated resprouting, flowering, and seed release and germination. Biological Reviews 94, 903-928.

Lamont BB, Pausas JG, He T, Witkowski ETF, Hanley ME. 2020. Fire as a selective agent for both serotiny and nonserotiny over space and time. Critical Reviews in Plant Sciences 39, 140-172.

Lamont, BB, Miller, BP, Enright, NJ, Yan, ZG 2021. Isolation and self-regulation processes promote plant species diversity in simulated postfire microsites. Acta Oecologica doi: 10.1016/j.actao.2021.103795

Mackenzie BDE, Auld TD, Keith DA, Hui FKC, Ooi MKJ. 2016. The effect of seasonal ambient temperatures on fire-stimulated germination of species with physiological dormancy: a case study using Boronia (Rutaceae). PLoS One doi: 10.1371/journal.pone.0156142

Midgley JJ, Viviers M. 1990. The germination of seeds from heated serotinous cones of eight shrubland species. South African Forestry Journal 155, 5-9.

Moreira B, Tormo J, Estrelles E, Pausas JG. 2010. Disentangling the role of heat and smoke as germination cues in Mediterranean Basin flora. Annals of Botany 105, 627-635. 
Morris EC. 2000. Germination response of seven east Australia Grevillea species to smoke, heat exposure and scarification. Australian Journal of Botany 48, 179-189.

Newton RJ, Mackenzie BDE, Lamont BB, Gomez-Barreiro P, Cowling RM, He T. 2021.

Fire-mediated germination syndromes in Leucadendron (Proteaceae) and their ecological correlates. Oecologia 196, 589-604.

Noodén LD, Blakley KA, Grzybowski JM. 1985. Control of seed-coat thickness and permeability in soybean: a possible adaptation to stress. Plant Physiology 79, 543-545.

Preston CA, Baldwin IT. 1999. Positive and negative signals regulate seed germination in the post-fire annual, Nicotiana attenuata. Ecology 80, 481-494.

Richard GA, Zabala JM, Cerino MC, Marinoni LDR, Beutel ME, Pensiero JF. 2018.

Variability in hardseededness and seed-coat thickness of three populations of Desmanthus virgatus (Fabaceae, Mimosoideae). Grass Forage Science 73, 938-946.

Rundel PW, Arroyo MTK, Cowling RM, Keeley JE, Lamont BB, Pausas JG, Vargas P. 2018. Fire and plant diversification in Mediterranean-climate regions. Frontiers in Plant Science doi: 10.3389/fpls.2018.00851

Tangney R, Merritt DJ, Callow JN, Fontaine JB, Miller BP. 2020. Seed traits determine species responses to fire under varying soil heating scenarios. Functional Ecology 34:19671978.

Zirondi HL, Silveira FAO, Fidelis A. 2019. Fire effects on seed germination: heat shock and smoke on permeable vs impermeable seed coats. Flora doi: org/10.1016/j.flora.2019.03.007 
Table 1. 40 Leucadendron species whose seeds were subjected to simulated fire [viz., smoke (water) and/or heat $\left(80^{\circ} \mathrm{C}\right.$ for $\left.\left.20 \mathrm{~min}\right)\right]$ plus a dry, $40 / 20^{\circ} \mathrm{C}$ diurnal pre-treatment to simulate a warm postfire summer before incubation at optimal winter temperatures (moist, $20 / 10^{\circ} \mathrm{C}$ ). Seeds plant-stored $(\mathrm{P})$, or soil-stored (S). Fruit a nutlet (N) or flattened and winged (W). L. nervosum has small spindle-shaped achenes with long hairs that are unlike other nutlets listed here but is treated as $\mathrm{W}$ as it is winddispersed. Seed coat $=$ arithmetic mean seed-coat thickness. Water content after imbibition for $72 \mathrm{~h}$. SDs were 10-20\% of the means and have not been included here. Germination data are posterior means. *Since this study was undertaken this species was found to be L. galpinii, although it was from a different collection, has slightly different propeties and is retained here.

\begin{tabular}{|c|c|c|c|c|c|}
\hline Leucadendron & $\begin{array}{l}\text { Plant- } \\
\text { or soil- } \\
\text { stored }\end{array}$ & $\begin{array}{c}\text { Nutlet } \\
\text { or } \\
\text { winged }\end{array}$ & $\begin{array}{c}\text { Seed } \\
\text { coat } \\
(\mu \mathrm{m})\end{array}$ & $\begin{array}{c}\text { Imbi } \\
\text { b } \\
\text {-ition } \\
(\%)\end{array}$ & $\begin{array}{c}\text { Germinatio } \\
n \\
\text { of controls } \\
(\%)\end{array}$ \\
\hline album & $\mathrm{P}$ & $\mathrm{N}$ & 200 & 37.0 & 36.2 \\
\hline argenteum & $\mathrm{P}$ & $\mathrm{N}$ & 568 & 28.5 & 91.0 \\
\hline brunioides & S & $\mathrm{N}$ & 316 & 38.5 & 3.6 \\
\hline chamalaea & S & $\mathrm{N}$ & 228 & - & 81.1 \\
\hline comosum & $\mathrm{P}$ & W & 24 & 57.3 & 99.8 \\
\hline coniferum & $\mathrm{P}$ & W & 33 & - & 99.7 \\
\hline corymbosum & S & $\mathrm{N}$ & 160 & - & 24.7 \\
\hline discolor & $P$ & W & 63 & - & 99.0 \\
\hline dregei & $\mathrm{P}$ & $\mathrm{N}$ & 250 & - & 95.5 \\
\hline elimense & S & $\mathrm{N}$ & 237 & 28.8 & 10.0 \\
\hline eucalyptifolium & $\mathrm{P}$ & W & 39 & - & 100.0 \\
\hline flexuosum & $\mathrm{P}$ & W & 48 & - & 100.0 \\
\hline foedum & $P$ & W & 44 & - & 100.0 \\
\hline galpinii & $\mathrm{P}$ & $\mathrm{N}$ & 320 & 32.7 & 59.5 \\
\hline gandogeri & $\mathrm{P}$ & W & 44 & - & 28.8 \\
\hline lanigerum & $P$ & W & 53 & - & 18.0 \\
\hline laureolum & $\mathrm{P}$ & W & 40 & - & 100.0 \\
\hline laxum & S & $\mathrm{N}$ & 234 & 34.1 & 28.8 \\
\hline linifolium & $\mathrm{P}$ & $\mathrm{N}$ & 575 & 31.6 & 18.0 \\
\hline loranthifolium & S & $\mathrm{N}$ & 154 & - & 24.9 \\
\hline meridianum & $\mathrm{P}$ & W & 31 & - & 100.0 \\
\hline microcephalum & $\mathrm{P}$ & W & 94 & - & 99.7 \\
\hline modestum* & $\mathrm{P}$ & $\mathrm{N}$ & 236 & - & 63.5 \\
\hline muirii & $\mathrm{P}$ & W & 24 & - & 99.4 \\
\hline nervosum & $P$ & $\mathrm{~N}$ & 57 & 67.8 & 98.2 \\
\hline nobilis & $\mathrm{P}$ & W & 27 & 55.5 & 99.8 \\
\hline procerum & $\mathrm{P}$ & W & 70 & - & 100.0 \\
\hline rourkei & $\mathrm{P}$ & W & 26 & 49.4 & 100.0 \\
\hline rubrum & $\mathrm{P}$ & $\mathrm{N}$ & 51 & - & 99.8 \\
\hline salicifolium & $\mathrm{P}$ & W & 58 & - & 99.8 \\
\hline salignum & $\mathrm{P}$ & W & 47 & - & 100.0 \\
\hline sericeum & S & $\mathrm{N}$ & 193 & - & 4.1 \\
\hline spissifolium & $\mathrm{P}$ & W & 57 & - & 99.0 \\
\hline stelligerum & $\mathrm{P}$ & W & 54 & - & 99.8 \\
\hline strobilinum & $\mathrm{P}$ & W & 50 & - & 100.0 \\
\hline teretifolim & $\mathrm{P}$ & W & 33 & - & 100.0 \\
\hline thymifolium & S & $\mathrm{N}$ & 505 & 38.0 & 24.9 \\
\hline tinctum & S & $\mathrm{N}$ & 955 & - & 48.1 \\
\hline uliginosum & $P$ & W & 140 & 40.9 & 88.1 \\
\hline xanthoconus & $\mathrm{P}$ & W & 103 & - & 100.0 \\
\hline
\end{tabular}


Table 2. Five possible dormancy-release/germination syndromes based on individual and the additive effects of heat $(\mathrm{H})$ and smoke $(\mathrm{S})$ on germination that should apply to all fire-prone species, with examples from this study of 39 Leucadendron species (excluding L. tinctum) and elsewhere if not observed here. $\pm=$ presence or absence of fire component, $\rightarrow=$ leads to treatment outcome. ( ) refers to likely mechanism of dormancy release as supported by relevant literature.

1. $\pm \mathrm{H} \rightarrow$ germination $\mathrm{x} \%=$ control

$\pm \mathrm{S} \rightarrow$ germination $\mathrm{x} \%$

$+\mathrm{H}+\mathrm{S} \rightarrow$ germination $\mathrm{x} \%$

Conclusion: neither $\mathrm{H}$ nor $\mathrm{S}$ required for promoting dormancy release (thin seed coat - already highly permeable)

Example: most serotinous Leucadendron species, especially if fruits winged

2. $\pm \mathrm{H} \rightarrow$ germination $\mathrm{x} \%=$ control

$+\mathrm{S} \rightarrow$ germination $\mathrm{y} \%>$ control

$+\mathrm{H}+\mathrm{S} \rightarrow$ germination $\mathrm{y} \%$, where $\mathrm{y}>\mathrm{x}$

Conclusion: $S$, but not $\mathrm{H}$, promotes dormancy release (moderately thick seed coat - catalysis)

Examples: most Leucadendron species with soil-stored seeds

3. $+\mathrm{H} \rightarrow$ germination $\mathrm{x} \%>$ control

$\pm \mathrm{S} \rightarrow$ germination $\mathrm{y} \%=$ control

$+\mathrm{H}+\mathrm{S} \rightarrow$ germination $\mathrm{x} \%$, where $\mathrm{x}>\mathrm{y}$

Conclusion: $\mathrm{H}$, but not $\mathrm{S}$, promotes dormancy release (thick seed coat increased permeability)

Examples: none among 39 Leucadendron species, possibly L. tinctum (Brown and

Dix 1985), most hard-seeded legumes

4. $+\mathrm{H} \rightarrow$ germination $\mathrm{x} \%>$ control

$+\mathrm{S} \rightarrow$ germination $\mathrm{y} \%>$ control

$+\mathrm{H}+\mathrm{S} \rightarrow$ germination $=\mathrm{x}$ or $\mathrm{y} \%$, whichever is the greater

Conclusion: $H$ and $S$ probably affect the same dormancy-release process

(moderately thick seed-coat - increased permeability?)

Examples: some species with soil-stored seeds, for Leucadendron species: $L$.

elimense, L. thymifolium

$5 \mathrm{~A} .+\mathrm{H} \rightarrow$ germination $\mathrm{x} \%>$ control

$+\mathrm{S} \rightarrow$ germination $\mathrm{x} \%>$ control

$+\mathrm{H}+\mathrm{S} \rightarrow$ germination $>\mathrm{x} \%$

Conclusion: $\mathrm{H}$ and $\mathrm{S}$ promote different dormancy-release processes

(moderately thick seed-coat - increased permeability, catalysis)

Examples: none among 39 Leucadendron species, Mimosa leiocephala (Zirondi et al. 2019)

5B. $+\mathrm{H} \rightarrow$ germination $\mathrm{x} \%$

$+\mathrm{S} \rightarrow$ germination $\mathrm{y} \%$

$+\mathrm{H}+\mathrm{S} \rightarrow$ germination $>$ ( $\mathrm{x}$ or $\mathrm{y}) \%$, whichever is the greater

Conclusion: $H$ and $S$ promote different dormancy-release processes

(moderately thick seed-coat - increased permeability, catalysis)

Examples: none among 39 Leucadendron species, Mimosa somnians (Zirondi et al. 2019) 


\section{Figures}

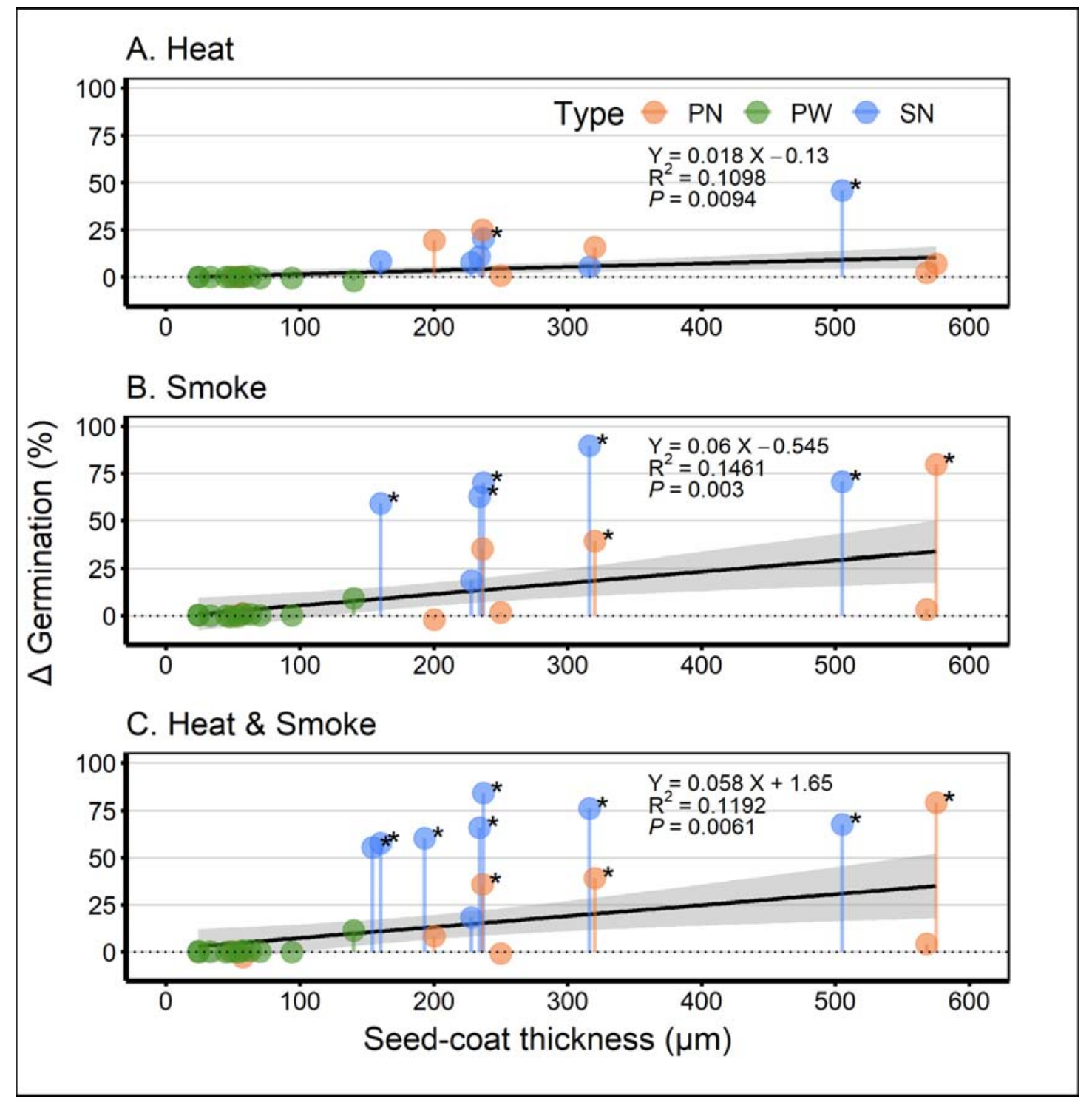

Figure 1. Relationship between seed-coat thickness and germination increase ( $\Delta=$ difference between average treatment and average control germination) for all species whose controls were $<100 \%$ germination. The 13 species with $100 \%$ germination among the controls are represented here by one value to minimize bias in the data. A. Following heat pre-treatment $\left(80^{\circ} \mathrm{C}\right.$ for $\left.20 \mathrm{~min}\right), \mathrm{B}$. Following smoke water pre-treatment, and C. Following both heat and smoke. Seed types are Plant-stored Nutlets (PN, orange), Plant-stored Winged achenes (PW, green) and Soil-stored Nutlets (SN, blue). Biologically significant results (according to Newton et al., 2021) have an asterisk above/next to them. Linear regression lines are also given with their equations and probabilities, together with $95 \%$ confidence interval in grey. Germination averages were calculated from posterior mean germination values extracted from Table S5 of Newton et al. (2021) 


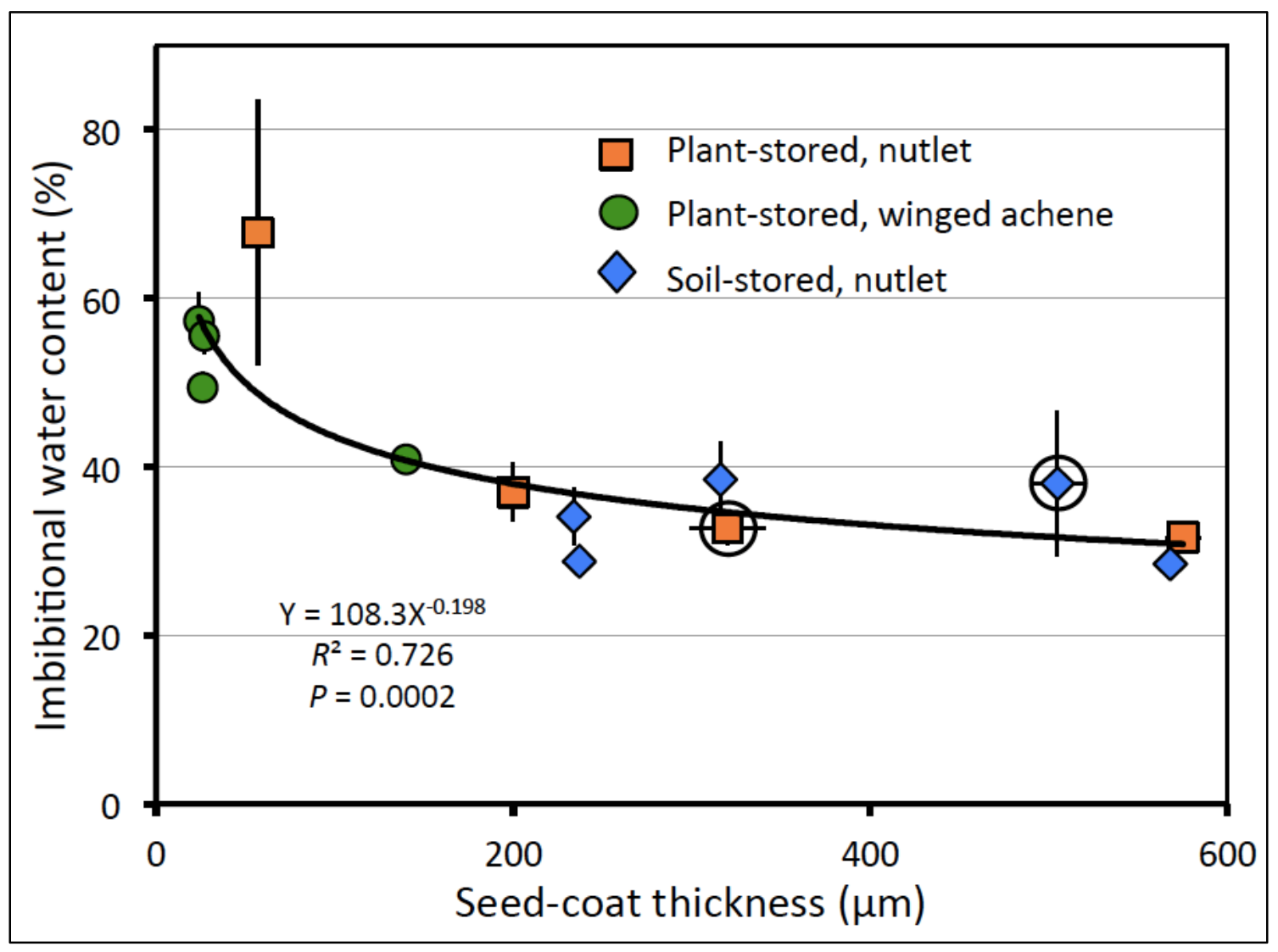

Figure 2. Mean \pm SE imbibitional water contents after $72 \mathrm{~h}$ of soaking for the 13 species selected to represent the range of mean \pm SE seed-coat thicknesses. The two species that responded to both smoke and heat are ringed. The best-fit curve to the data is given as well as its formula and probability. 


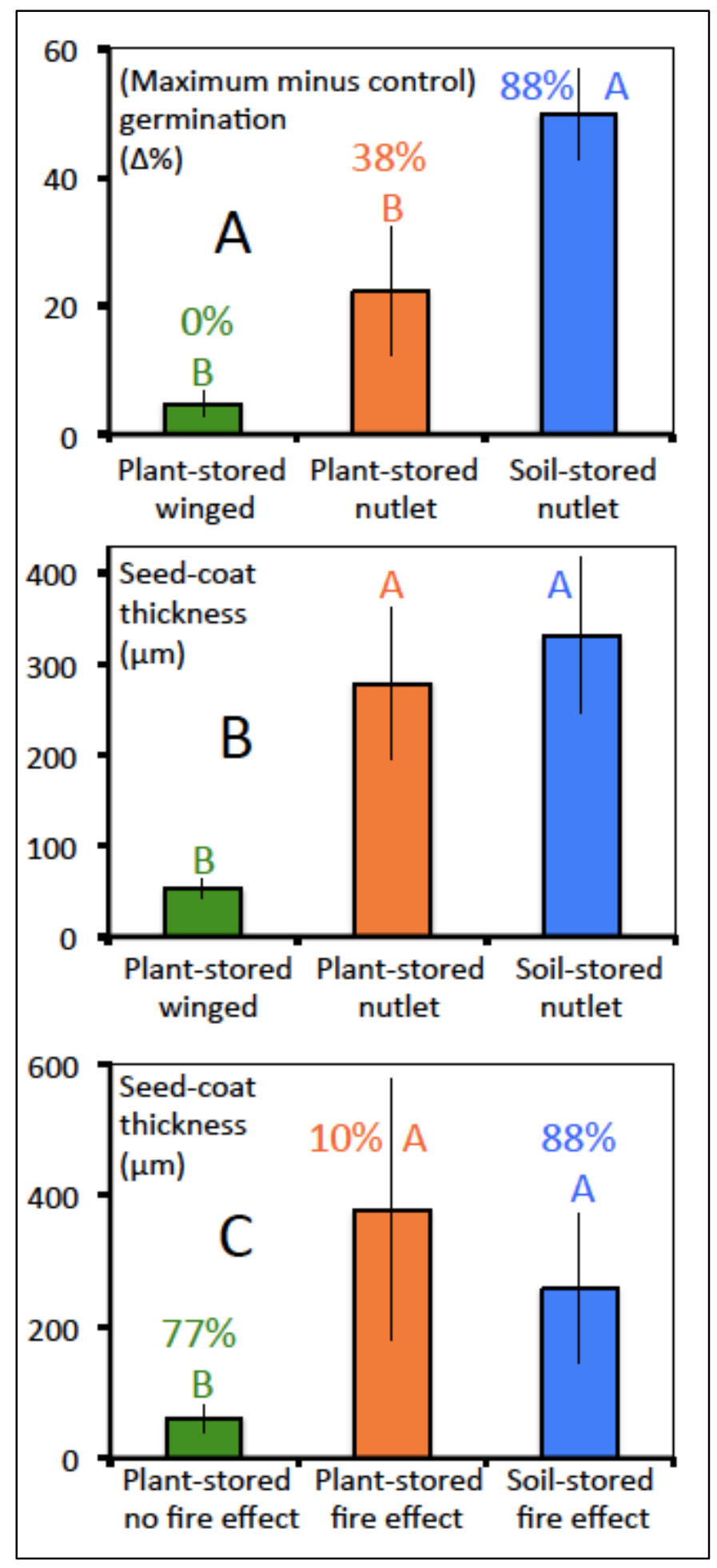

Figure 3. Means $\pm 95 \%$ CIs for all species in each of three seed categories based on storage location and fruit morphology, plus results for ANOVA of weighted means followed by Tukey's HSD test - letters significantly different at $P<0.01$. A. (Maximum value among the three firetype treatments minus control) germination levels plus $\%$ of species showing biologically significant differences within each category; B. Seed-coat thicknesses for the three categories; and C. Seed-coat thicknesses plotted against plant- or soil-stored seeds that do or do not have biologically significant germination levels in response to a fire (smoke) property plus \% of species showing biologically significant differences within each category. 


\section{Figure legends}

Figure 1. Relationship between seed-coat thickness and germination increase $(\Delta=$ difference between average treatment and average control germination) for all species whose controls were $<100 \%$ germination. The 13 species with $100 \%$ germination among the controls are represented here by one value to minimize bias in the data. A. Following heat pre-treatment $\left(80^{\circ} \mathrm{C}\right.$ for $\left.20 \mathrm{~min}\right)$, B. Following smoke water pre-treatment, and C. Following both heat and smoke. Seed types are Plant-stored Nutlets (PN, orange), Plant-stored Winged achenes (PW, green) and Soil-stored Nutlets (SN, blue).

Biologically significant results (according to Newton et al., 2021) have an asterisk above/next to them. Linear regression lines are also given with their equations and probabilities, together with $95 \%$ confidence interval in grey. Germination averages were calculated from posterior mean germination values extracted from Table S5 of Newton et al. (2021)

Figure 2. Mean \pm SE imbibitional water contents after $72 \mathrm{~h}$ of soaking for the 13 species selected to represent the range of mean \pm SE seed-coat thicknesses. The two species that responded to both smoke and heat are ringed. The best-fit curve to the data is included as well as its formula and significance.

Figure 3. Means $\pm 95 \%$ CIs for all species in each of three seed categories based on storage location and fruit morphology, plus results for ANOVA of weighted means followed by Tukey's HSD test letters significantly different at $P<0.01$. A. (Maximum value among the three fire-type treatments minus control) germination levels plus $\%$ of species showing biologically significant differences within each category; B. Seed-coat thicknesses for the three categories; and C. Seed-coat thicknesses plotted against plant- or soil-stored seeds that do or do not have biologically significant germination levels in response to a fire (smoke) property plus \% of species showing biologically significant differences within each category. 